\title{
El Diario llustrado: modernidad y ensoñación identitaria
}

\author{
Por Carlos Ossandón
}

“...la forma es lo que primeramente toca a las muchedumbres" Rubén Darío Prefacio a Cantos de vida y esperanza (1905)

1. En la medida que nos internamos en el espacio periodístico chileno de la segunda mitad del siglo XIX e inicios del XX, se va haciendo ostensible el peso que adquieren unos principios formales o unas lógicas de distribución de la información que se imponen por encima de las prerrogativas de los "autores" y de sus "estilos" 2 . Se trata, más globalmente dicho, de la constitución en ese período de un sistema de comunicación social que ya es posible reconocer como moderno. En otro trabajo, hemos señalado que este sistema, que se confunde con lo que clásicamente se denomina periodismo liberal, si bien da cuenta de fuerzas sociales y políticas distintas y en competencia, ya no es mera superficie de proyección de dichas fuerzas. Sin desconocer su relación con los grandes poderes y también con los más pequeños emergentes, pero más allá de un carácter puramente instrumental o "simbiótico", este sistema es tal precisamente porque construye artefactos y "significaciones" propias. El carácter no puramente "diluido" o más "autónomo" es pues su específica novedad, en contraste, claro está, con anteriores paisajes comunicacionales. El desarrollo de la "empresa" periodística moderna y de unas estrategias periodísticas más conscientes de sí, de un mercado noticioso y de bienes simbólicos que puede imponer sus propios ritmos y demandas, el mayor espacio y peso que toma el avisaje y las transacciones comerciales, la ampliación y diversificación de medios y formatos, la inicial consolidación de narrativas estandarizadas o de géneros propiamente periodísticos y de profesionales de la prensa, el desarrollo de intereses y gustos nuevos y de un público lector más numeroso, diversificado y anónimo, así como la circulación de distintas identidades y perspectivas políticas, son algunos de los nuevos factores que caracterizan al sistema comunicacional en formación3.

Lo que queremos decir, más particularmente, es que las publicaciones periodísticas que "marcan" este período instalan todo un juego de lenguajes y secciones, de saberes y géneros, que las transforman en unas instancias de enunciación cuya articulación tiene que ver más con dimensiones estratégicas o comunicacionales que con "autorías", rúbricas individuales o "desvíos" subjetivos. Es el propio espaciamiento periodístico o su relevancia comunicativa, más que los enunciados mismos o la inscripción de unas "firmas", los que determinan las singularidades de estos aparatos. Por otra parte, las dispersiones, cortes o heterogeneidades de los textos periódicos, la existencia de escrituras sectoriales o regionales, la selección y distribución del material, así como su forma global o "gestalt", tienen ahora una centralidad capaz de desplazar como tendencia predominante unos textos articulados a partir de otros principios, visibles en la primera mitad del XIX en Chile: la "barricada" o el parapeto político, puramente instrumental, carente de peso periodístico propio (v.gr. El Hambriento y El Canalla de la década de 1820); la doctrina o el imperativo de dilucidación ideológica (v.gr. La Revista Católica fundada en 1843); la proclama o el llamamiento (v.gr. La Asamblea Constituyente de 1858); la necesidad de establecer puentes con los países "adelantados", de divulgar conocimientos o de "poner al día" (v.gr. El Museo de Ambas Américas editado en Valparaíso desde 1842); la colaboración en la fundación del Estado-nación o en la instalación de bases jurídico-culturales (v.gr. El Araucano animado por Andrés Bello desde 1830), entre otros principios. Ahora, en cambio (a principios del XX principalmente), se observan unos dispositivos que ofrecen unos "perfiles" o unas identidades móviles, no igualables a otras identidades, y que no pueden ser concebidos como espacios inertes, meros reflejos de dinámicas o de sujetos exteriores a ellos mismos. Para decirlo en una palabra, la prensa cambia su carácter 4 y se transforma en un importante nuevo actor. En tanto que actor se apropia de un habla, construye una "personalidad" en cierto grado irreductible, que interactúa o entra en diálogo con otras hablas y prácticas, dentro de esa obra o proceso mayor llamado modernización. Es claro, sin embargo, que la "autonomía" ganada es sólo 
relativa y está permanente afectada por presiones o tensiones de distinta naturaleza y peso, de carácter principalmente ideológico, político y económico.
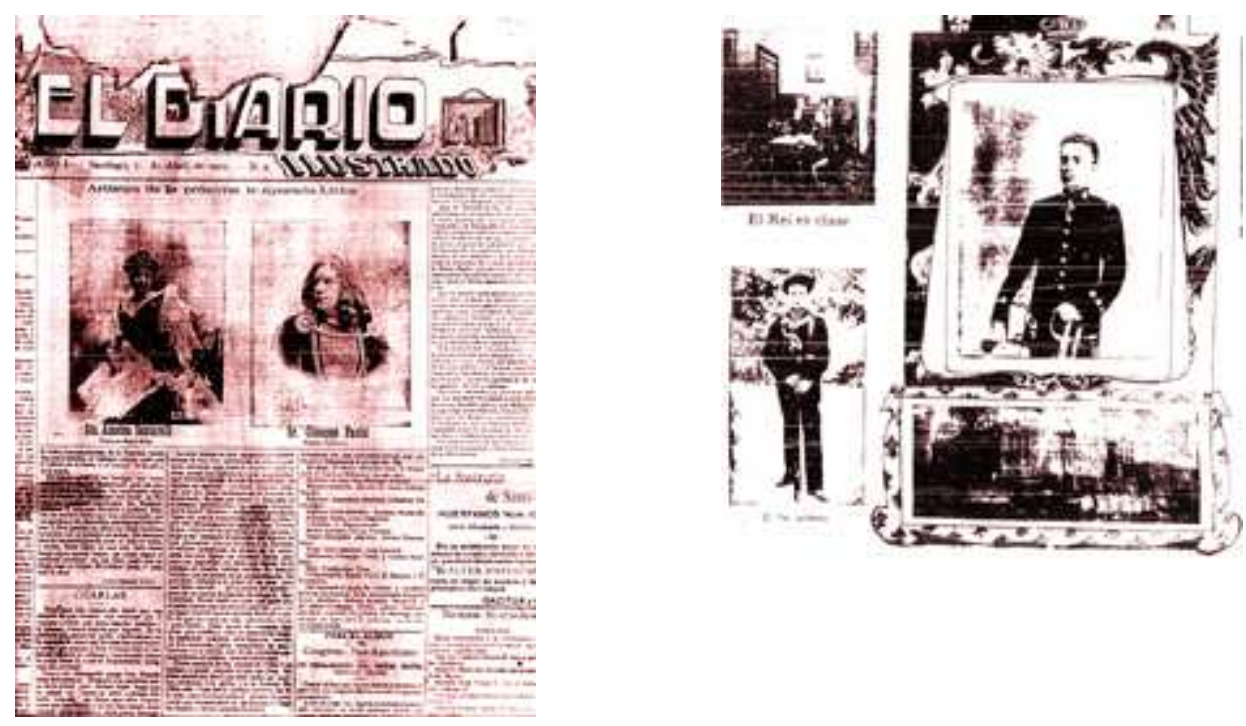

figura 1

figura 2

2. Es precisamente una de estas tensiones la que puede guiar la descripción, no de la "ideología" principalmente, sino de las condiciones materiales y discursivas de uno de los periódicos que prácticamente inauguró el siglo XX, marcando una influencia importante durante más de 60 años en Chile. Nos referimos a El Diario llustrado fundado en Santiago por Ricardo Salas Edwards, cuya existencia se extendió desde el 31 de marzo de 1902 hasta el 23 de octubre de 1970. Este diario, concebido "al estilo del Daily Graphic, proveniente de la ciudad de Londres" 5 , introdujo una importante innovación: "el uso del fotograbado en reemplazo del sistema de litograbado". Esta innovación "que permitió la publicación de fotografías por primera vez en el país" provocó, según Alfonso Valdebenito, "una verdadera revolución en el periodismo nacional"6. En su primer año habría alcanzado un tiraje de 2.000 ejemplares diarios, obteniendo en los años siguientes tirajes bastante más elevados : 30.000 ejemplares, según se dice, en 1908 y, al parecer, más de 100.000 después del primer gobierno de Ibañez. Unos años antes de la creación de la magazinesca Zig-Zag (1905) y de la revista infantil El Peneca (1908), un poco después de la fundación en Santiago de El Mercurio (1900) que irrumpía impetuosamente agotando en un instante 9.000 ejemplares7, y el mismo año de nacimiento de Las Ultimas Noticias8, por citar sólo algunos ejemplos significativos, es claro que la creación de El Diario Ilustrado no es un botón aislado sino manifestación de un proceso mayor que involucró nuevos formatos y públicos en los inicios del siglo XX en Chile. Más precisamente, este nuevo diario, que para uno de sus competidores aparecía preocupantemente "bien mirado por la gente"9, es expresión de ese nuevo carácter que recién destacábamos de la prensa chilena, que se aprecia desde la segunda mitad del XIX y más claramente en los primeros años del XX. Ello junto, claro está, a otros diarios igualmente importantes de más "vieja" data, como El Ferrocarril de Santiago (1855) y El Mercurio de Valparaíso (1827).

Adentrémonos en las singularidades de una forma ciertamente no "innata" sino "adventicia" y que más globalmente vista se confunde con las formas o "significaciones" características del periodismo moderno. Examinemos cómo coexisten en El Diario Ilustrado las nuevas condiciones del periodismo moderno con las pretensiones de una elite, que busca marcar una presencia en el terreno específico de la prensa y del espacio público como simultáneamente en el de unos signos y sensibilidades guiados por principios más bien identitarios. Como se sabe, El Diario llustrado estuvo ligado al conservadurismo, y más nítidamente a partir de 1908 cuando su fundador lo traspasa a "un grupo de activos políticos conservadores", cuestión que va a cambiar su línea editorial, algo más “independiente” en un comienzo. Según Raúl Silva Castro, después del intento inicial de Ricardo Salas de hacer vivir al diario lejos de la lucha de los partidos, este "intervino no sólo en aquella lucha ardiente /.../ sino que además cobró en 
ella un puesto de adalid valiente y audaz. Las campañas de oposición al gobierno de Alessandri (1920-24) y al de Ibañez (1927-31) prueban que la previsión del señor Salas Edwards se había quedado corta"10.

En sus primeros años de vida, en cambio, visiblemente en 1902 que es el año que examinamos en este artículo (en sus dos primeros meses principalmente), El Diario Ilustrado pone en práctica uno de los mecanismos de validación más poderosos de la prensa moderna: nos referimos al tratamiento ponderado por un lado y circunscrito por el otro que hace de los conflictos de interés público. A raíz de una huelga de cobradores y conductores de tranvía, el meeting, los desórdenes y la carga de la policía que le siguieron, el diario procura, ya desde los subtítulos que describen el hecho11, dar cuenta de los ingredientes más visibles del mismo, construyendo bajo la guía de estos subtítulos un relato mesurado o imparcial (n.1, 31 de marzo de 1902); cuestión que se mantiene en el número siguiente, del 1 de abril de 1902, al entrevistar por igual (técnica muy usada por la prensa moderna) a los distintos actores involucrados en los hechos entre huelguistas y policía. En este mismo número se publica también un artículo de Luis Orrego Luco que aboga por un "sistema de arbitrajes" que permitiría dar "a cada uno lo suyo". Ciertamente el diario no siempre será así de "neutral": en la crónica "De la huelga y otros excesos" de Antuco Antúnez ya el sólo título ilustra bien hacia donde quiere ir (n. 4, 3 de abril de 1902)12. Por otro lado, es fácil advertir que el hecho en cuestión, su relato, sus fotografías, entrevistas y comentarios, aun teniendo un espacio importante en los dos números analizados, no empapan todo el cuerpo del periódico ni hacen tambalear tampoco la diversidad de secciones y avisos que le son característicos. Al estilo ponderado de enfrentar el hecho se le une su circunscripción precisa dentro del propio espaciamiento periodístico: el carácter no totalizador ni desbordante del hecho en la propia superficie del periódico contribuye a su "normalización", que no parece requerir de operaciones ideológicas adicionales o más abiertas. La posibilidad de des-cubrirse o de quitarse el disfraz, de dejar los recatos a un lado y de exhibir un rostro, no es pues un imperativo ineludible para la prensa moderna.

Junto a este importante mecanismo, que tiene que ver tanto con el modo como se caracterizan los hechos como con su localización y límites dentro del texto periodístico, El Diario llustrado da cuenta de una tensión que parece afectar su núcleo. Si en el terreno social, en la propia descripción del hecho que comprometió a huelguistas y policía, el diario no desea "cargar las tintas" (al menos, no demasiado), y lo que hace es más bien instalarlo dentro de la diversidad de nudos o cortes que el diario efectúa y que operan como un "mapa" de la ciudad (ya volveremos sobre esto), en el terreno de las actividades del teatro lírico y de sus artistas, por ejemplo, el diario no ahorra adjetivos, no tiene empacho en mostrar su preferencias y no se ubica ni en un lugar "neutral" ni tampoco de "interés general". No percibiendo otros litigantes en el plano cultural el periódico no se siente en falta respecto del imperativo jurídico: audi alteram partem. A pesar que los "acontecimientos" del Teatro Municipal también sufren esa política de demarcación o de circunscripción que describíamos más atrás, que no es "discursiva" sino "espacial", ya no es la ponderación ni el deseo de "arbitrar" o publicar manifestaciones "representativas" de los distintos litigantes culturales lo que guía estas secciones. La lógica que las explica hay que buscarla más en las compulsiones "identitarias" de la elite que en los fragmentos o diversidades que sintetizan las páginas de esta publicación. Es importante decir, sin embargo, que esta elite se está nutriendo de distintas fuentes socio-culturales13.

En el n. 2, del 1 de abril de 1902, se reproducen en primera página, inmediatamente más abajo del título del diario, los retratos de dos importantes artistas de la temporada lírica: de la renombrada soprano único absoluto señora Amadea Santarelli, "primera dama lírica”, y del señor Giuseppe Pacini primer barítono absoluto y cuya poderosa voz ya había conocido con anterioridad el público de Santiago (ver figura n. 1). Se reseña además el elenco completo de la nueva compañía lírica del Teatro Municipal. Al respecto se dice: "Al aproximarse la estación de las aburridas noches de invierno, es natural que la expectativa de los aficionados a la ópera se dirija hacia esa especie de incógnita que se llama el personal de la nueva compañía. Por fortuna para el prestigio de nuestra primera escena, las noticias que nos llegan de los grandes centros artísticos son enteramente favorables a dichas expectativas, y vienen a despejar de feliz manera aquella que suele ser la pesadilla de los abonados y habitués". Es 
evidente que esta "noticia" se enmarca dentro de las prácticas culturales, expectativas y gustos de unos "aficionados" que padecen unas "pesadillas" que no pretenden ser universales. Los gustos y expectativas no se reducen, sin embargo, al arte lírico. El diario destaca también al "notable transformista" señor Frégoli y la muy buena concurrencia que tuvo en el Teatro Municipal obteniendo "nutridos aplausos, especialmente en el ParisConcert" (n. 23, 23 de abril de 1902). Con mucha regularidad destaca asimismo los estrenos y representaciones del Teatro Santiago que solía ser frecuentado "por lo más distinguido de nuestro mundo social" (n. 36, 6 de mayo de 1902). En este Teatro se presentó el "nuevo cuadro de zarzuela organizado por la empresa Ansaldo" que tuvo una concurrencia tan numerosa como distinguida, al punto que "uno de los palcos del proscenio estaba ocupado por S.E. el Presidente de la República" (n. 3, 2 de abril de 1902); en él tuvo lugar la puesta en escena, dice el diario, de "El Ultimo Chulo, obra en que se luce particularmente la señorita Sánchez y el tenor cómico Luis Periú" (n. 5, 4 de abril de 1902); la representación de la zarzuela, algo escandalosa para la época, El Seminarista, que cuenta la historia de un joven que cuelga los hábitos y se va a París (n. 24, 24 de abril de 1902); o de la "chistosa zarzuela La Golfemia, parodia de la Bohème" (n. 32, 2 de mayo de 1902), entre tantas más. El diario informa además, aunque no con la "trascendencia" que le confiere a las obras y artistas del género lírico, de las gracias de Pepe Vila (n. 2, 1 de abril de 1902), de su partida de la capital, o del estreno del juguete cómico Salvarse en una tabla de Salvador Lastra en el mismo Teatro Santiago (n.8, 8 de abril de 1902). La sensibilidad que enseña o estimula el diario, si ser siempre "refinada", y muchas veces cercana a lo "ligero", poco tiene que ver, sin embargo, en lo que a música se refiere, con aquellos temas que se escuchaban en chinganas o en algún alejado restaurante. No es de su interés reseñar espectáculos circenses ni "luchas romanas" ni representaciones en teatros de otro "rango" como el Apolo por ejemplo, cuyos habitués solían convertir en urinarios la vía pública14. Estos son, pues, los límites estéticos que el diario se autoimpone.

Pero esto no es lo más importante desde el punto de vista del análisis. Lo que no parece cuadrar es el modo cómo se conjugan determinadas preferencias estéticas de El Diario llustrado con ese "sentido común" no agresivo que irradian sus comentarios (tenemos siempre como referencia básica los primeros meses de 1902) por un lado, y con ese pretendido "universalismo" que sus diversas secciones enseñan, por el otro. Esto se podría decir también de otros diarios importantes que, al igual que en El Diario llustrado, publican actividades del Municipal, del Teatro Santiago y del Club Hípico; asimismo matrimonios, "fiestas de fantasía", primeras comuniones y otros protocolos que comprometen a la elite principalmente. Sin embargo, lo que hace la "diferencia" del diario que examinamos respecto de otros periódicos (El Ferrocarril y El Mercurio de Santiago, por ejemplo) no es tan sólo una cuestión de grado (de más o menos interés por estos temas), sino sobre todo la impronta que dejan unas "instantáneas", cuyos "contenidos" (retratos de "grandes" personajes, por ejemplo) terminan por desequilibrar o por hacer manifiestas unas "ostentaciones" que en los dos diarios citados pasan más inadvertidas, debido al peso de sus secciones ampliamente informativas. Pareciera, pues, que las propias predilecciones de El Diario llustrado en el plano del arte instalasen un "ruido" o estableciesen una distancia con una de las ambiciones más características de la prensa moderna: la de acceder a un público no sólo amplio sino también heterogéneo, constituido por distintas visiones e inclinaciones. Esta ambición, que ciertamente no es ajena al modo como dicha prensa se inventa un "alma" (o "perfil") y un "cuerpo" (o juego de secciones), no parece mantener una correspondencia con la centralidad que tienen los retratos de aquellos dos destacados cantantes líricos, la soprano y el barítono, publicados en el n. 2 del 1 de abril de 1902. La tensión se debilita, sin embargo, cuando se constata la equivalencia o nivelación que los tópicos del grand monde sufren en su relación o convivencia con temas de distinto carácter. No habría que olvidar, por último, que esos tópicos serán pronto recuperados por las revistas magazinescas que harán de estas exhibiciones un cierto "festín", formando parte de esos distintos intereses o "atracciones" que nutren el nuevo sistema de comunicación social. Estas exhibiciones no serán los únicos rasgos magazinescos que El Diario Ilustrado y otros periódicos proyectarán: también la moda, los banquetes de clausura, los centenarios de escritores, los consejos para protegerse de las altas temperaturas y otras curiosidades que preparan lo que algunos caracterizan hoy como la "sociedad del infoentretenimiento" que trae, entre tantas otras cosas, unas ofertas noticiosas que semejan verdaderos "cócteles" de temas, sabores y estilos diversos 15. 
3. Es claro que las "singularidades" descritas no alejan al Diario Ilustrado del nuevo carácter que toma la prensa en Chile en el período que examinamos. Por de pronto, su "cuerpo" no es muy distinto de lo que se ve en otros periódicos importantes de la época: los cablegramas extranjeros, las noticias del día, el sport, las notas sociales, las opiniones políticas, las "charlas mundanas" de Froufrou (un hablante femenino), el folletín (que se inaugura con un cuento de Sir Arthur Conan Doyle), los avisos comerciales, etc., son los tópicos a través de los cuales El Diario Ilustrado construye unas "temporalidades" y unas "espacialidades" segmentadas, que son más potentes que los modos más directamente "discursivos", estables o "ideológicos" de "representación"16. Estos tópicos, cuya arbitrariedad no siempre es fácil de captar, se imponen como "naturales" y no necesitan, por lo tanto, de autojustificaciones; operan como "incisiones", que más que mentir cortan, a diario y sin dolor; son hendiduras o fisuras que no parecen tales o que no se dejan reconocer como lo que son. Dotado de estas poderosas y más consolidadas "dispersiones" o "cortes", el periódico cree, además, que la modernidad de su prensa o la impresión en ella de "grabados tan finos y perfectos como los que ya hemos publicado" (n. 6, 6 de abril de 1902), y sus fotografías 17, le ha permitido colocarse en corto tiempo "en el rango de los de mayor circulación de la capital" (n. 9, 9 de abril de 1902).

El Diario Ilustrado configura también una "forma" que es algo más que las "dispersiones" o "fisuras" mencionadas o la novedad de sus fotografías. Dicha "forma" no habría que entenderla como una especie de "continente" que en sí "contiene" unos "contenidos". Decir que es una "forma" no asimilable a sus "dispersiones" o "cortes" no equivale a afirmar, por otro lado, que dicha "forma" le cae por encima o por afuera a estas "incisiones". Tampoco la concebimos como la simple proyección en el papel impreso de la nueva experiencia moderna o de aquellas hablas o tópicos propios de una ciudad que ha dejado de ser aldea. Hemos creído toparnos antes bien con una "diferencia" que se instala como una "presencia" más, al lado de otras presencias o diferencias igualmente constituyentes del proceso modernizador. Contribuye así a poblar una modernidad que, en las primeras décadas del siglo XX en Chile, estaba ya siendo poblada por un conjunto no menor de artefactos nuevos, tales como tranvías eléctricos, cine, aeroplanos, automóviles, teléfonos, etc. 18
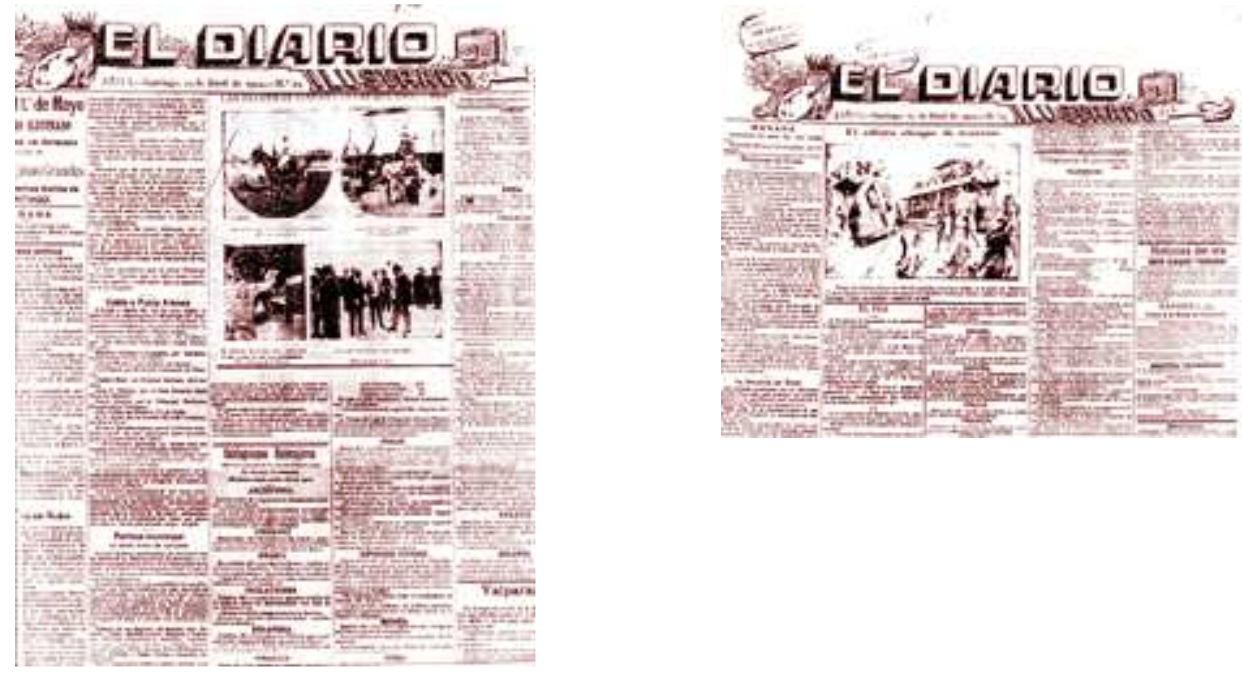

figura 3

figura 4

Con el correr del tiempo no será sólo la "noticia" sino más propiamente el periódico como "forma" el que se transformará en un "suceso" físico y mental. No es todavía éste el tiempo del diario que examinamos. Habrá que esperar varias décadas, o el advenimiento del "posmodernismo como pauta cultural dominante" (Fredric Jameson), para comprobar más fehacientemente cómo el imperio de los "significantes" o de las distribuciones visuales adquieren un poder capaz de arrasar con textos más dependientes de "contenidos" e incluso de "voluntades políticas". Por ahora aceptemos que el periódico de marras (así como otros de similar carácter), sin menoscabo de sus "incisiones" (contando con ellas, más bien), destaca una determinada organización o combinación, una "gestalt" se podría decir. En tanto tal, se 
proyecta mentalmente como un cierto "mapa" o campo visual y temporal, que suponemos indispensable como instrumento de orientación en el contexto de una ciudad y de unos "servicios" en expansión. Si como "forma" no es aún propiamente un "suceso", sí ya opera en cambio como "plano" y "brújula" a la vez. Este "mapa" no es, como decíamos más arriba, mera superficie de proyección de la experiencia moderna; más bien marca y prefigura los rumbos, lugares y también los tiempos en que se divide una ciudad que comienza a ser algo laberíntica o dificultosa. El periódico enseña así una "diferencia específica" que no se disuelve ni es simple "reflejo" de una "realidad" que, supuestamente instalada a sus espaldas, lo determinaría. Como todo "mapa" - salvo uno imaginado por Jorge Luis Borges no se confunde ni es su territorio. Es claro, sin embargo, que en este plano El Diario llustrado no se diferencia substantivamente de otros periódicos que responden al mismo modelo informativo y empresarial.

Lo que decimos tiene ciertamente correspondencia con la primacía que, sobre el resto del país, venía ejerciendo la ciudad de Santiago, los nuevos hábitos y niveles de consumo de sus habitantes, la proliferación de espectáculos, la inauguración reciente de tranvías eléctricos, los problemas de aglomeración y tránsito público, la expansión del espacio urbano y de los servicios públicos, entre otros factores de modernización19. Es lógico prever que estos desarrollos y cambios, que traducen una nueva fisonomía del paisaje urbano, exigirán también nuevos modos de dibujar o asimilar mentalmente estas novedades. Si recién afirmamos que el periódico no es un "reflejo" pasivo de factores que lo determinan desde fuera, con ello no queremos decir que la modelación de espacios y temporalidades la efectúa en el vacío o al modo de una creación divina ex nihilo. Es, más bien, una amalgama de prácticas, discursos y sensibilidades, privativos de una experiencia que una determinada visión ha venido identificando como "moderna" o "urbana", lo que el periódico "mapea", contribuyendo así a configurarla o a significarla.

Para Julio Ramos, el periódico es aquella articulación que permite "pensar la ciudad" como un espacio social coherente, y la lectura de periódicos es una práctica inseparable de la propias vivencias del sujeto urbano. Pero más importante aún, agrega, "es el hecho de que el periódico (como las tiendas modernas), en su propia organización del lenguaje (o de las cosas) queda atravesado por una lógica del sentido que también sobredetermina la disposición del espacio urbano. Lógica del sentido profundamente fragmentaria, desjerarquizadora" 20.

Muchos años antes, Friedrich Nietzsche caracterizó esta lógica como un "viscoso tejido conjuntivo" (p. 57), una especie de manojo de hilos finos y pegajosos, y al periodista como "esclavo del momento presente", como aquel que "ha llegado a substituir al gran genio, el guía para todas las épocas, el que libera del presente" (p. 58). Este tejido, que tanto extiende como reduce la cultura, y que es además pegadizo, tendría consecuencias lamentables para la propia configuración de la experiencia: sería "un medio específico de consuelo" (p. 175) que disipa o adormece los estremecimientos o riesgos de la cultura en su sentido fuerte. Este "medio" nada tendría que ver con una experiencia que remueve como vivencia íntima los grandes problemas de la existencia, y sería abiertamente agresivo contra un espíritu que, en su "inactualidad", no establece ninguna sintonía con las jergas, estéticas o articulaciones de un periodismo que domestica el horror y empobrece la afección 21.

4. Cualquiera que sea la potencialidad configuradora del periódico, como condición para "pensar la ciudad", como "mapa" o guía, o como estrechamiento de la experiencia o "consuelo", lo cierto es que éste no se reduce a ser tan sólo "medio", estableciendo una determinada "presencia" que, en el caso de El Diario Ilustrado y en particular de sus fotografías, exhibe unos sesgos que permiten entender mejor su lugar en el desarrollo de la prensa en Chile.

Se ha dicho que estos soportes tecnológicos (las fotografías) no operan autárquicamente, ni remiten a unidades mínimas preexistentes 0 independientes de configuraciones 0 estructuraciones más amplias y móviles22. Nos ha parecido, en efecto, que en El Diario Ilustrado estas configuraciones hacen sentir su peso en la propia determinación de las significaciones ligadas a la imagen: éstas hay que entenderlas, entonces, no como signos naturales o como códigos autónomos sino en relación con los sentidos que el periódico a su 
modo construye diariamente. Es ese doble carácter que hemos creído ver en este periódico, vehículo tanto de los nuevos factores de modernización como de las exigencias de una elite que requiere de espejos, proyecciones públicas y confirmaciones identitarias, el que interviene como punto de partida o de articulación de unos soportes tecnológicos cuya novedad habría que matizar23.

En el plano de estos soportes, los primeros números El Diario llustrado resaltan unos "derechos" que se imponen con cierta fuerza, aunque no acaparan todo el espacio visual, como veremos más adelante24. En el n. 1, del 31 de marzo de 1902, el periódico estrena en su primera página unas "instantáneas" que representan aspectos de las festividades de Semana Santa, la procesión del "Santo Sepulcro" por ejemplo. En el n. 2, del 1 de abril de 1902, en su primera página vienen, como ya se ha hecho notar, dos fotos de dos destacados artistas de la temporada lírica (recordemos una vez más a nuestra Amadea Santarelli, primera dama lírica, y a nuestro primer barítono absoluto señor Giuseppe Pacini) y en la página siguiente se publican fotos de representantes de la Legación Británica en Chile. En otros números el periódico publica fotografías de los monumentos del general José Manuel Baquedano, de Benjamín Vicuña Mackenna y de Victor Hugo, del "nuevo crucero chileno Chacabuco", del "blindado japonés Mi kasa" (el "buque de guerra más poderoso del mundo"), del Presidente y Vice-presidente de la Honorable Cámara de Senadores, entre otras figuras o realidades "importantes". Son estas representaciones, ligadas a grandes poderes, las que hegemonizan la escena visual. Se instalan así unos "derechos" que expresan bien una de las caras de El Diario Ilustrado, pero que más adelante tendrán que convivir con "derechos" de distinta naturaleza (ligados al "accidente" cotidiano, por ejemplo), necesarios para el desarrollo y masificación de la prensa.

En el momento que nos situamos, en cambio, la visibilidad no es todavía un bien dispuesto para una diversidad amplia de usos y en sus reinos entran básicamente los "personajes importantes". Estas primeras representaciones responden al modelo del "retrato" y están por ello fuertemente asociadas a la pintura25. Son muchos los ejemplos que se pueden citar en esta línea: foto de Enrique Maclver, candidato a senador, de Carlos E. Casanueva, ministro jubilado de la Excelentísima Corte Suprema recientemente fallecido, o de Ramón Barros Luco, organizador del nuevo Ministerio y delegado del Partido Liberal. El periódico viene así a proyectar públicamente un tipo de trabajo o de "modelo" bastante habitual en Chile desde la segunda mitad del XIX y que era ejecutado por retratistas itinerantes y fotógrafos establecidos26. Es claro, sin embargo, que esta costumbre, aun cuando tiene un mayor alcance público, se encuentra por otra parte severamente restringida en el diario que examinamos. Esta línea llega a su apoteosis o se "corona", valga la redundancia, con las 9 ilustraciones relativas a "la coronación de Alfonso XIII" (n. 47, 17 de mayo de 1902). Ellas cubren por completo la primera página, mostrando al nuevo rey de España tanto bajo "la dignidad destemporalizada del personaje notable", en el modelo del "retrato" (ver foto al centro de la página), como bajo "la naturalidad de una vida que, a pesar de estar marcada por el sello de lo público, no deja por ello de ser una vida como las demás"27: "el rey en familia", "el rey en clase" (ver figura n. 2). El contraste entre la "trascendencia" y la naturalización del mundo cotidiano del "personaje notable", que apunta a humanizarlo o a equipararlo con los mortales comunes y corrientes, o entre la "significación" de este personaje o su construcción como "monumento" y las aparentes nimiedades e "insignificancias" que también lo constituyen, será uno de los juegos o retóricas visuales corrientemente usadas por las nacientes revistas magazinescas (Zig-Zag, por ejemplo).

Junto a este tipo de fotografías, el periódico exhibe otras cuyos motivos son diversos: una fiesta escolar, plazas, un paseo campestre, un puerto pintoresco, caciques araucanos, un taller de carpintería, paisajes. No son propiamente "accidentes" o sucesos imprevistos, en la medida que su irregularidad o el grado de alteración que introducen en "el mundo de todos los días" se revela débil o poco escabrosa. A lo más se podría decir que se trata de "escenas" o de "acontecimientos" pero no en el sentido "accidental" del mismo. Recién en el n. 19 nos topamos por primera vez con un dibujo que representa un "accidente" ocurrido en Santiago (ver figura n. 3)28. Si bien poco a poco irá creciendo el espacio que se le conferirá a hechos recientes, cuya "accidentalidad" es diversa (en 1904, por ejemplo, la serie continuada de fotos "En el teatro de la guerra", referidas al conflicto ruso-japonés), en estos primeros 
meses hay muchas fotos que responden a un modelo "costumbrista" o "documental", aunque éstas no tienen la centralidad de las que se ciñen al modelo del "retrato" del "gran personaje".

Por último, no deja de ser revelador el "Concurso de Instantáneas fotográficas" que organiza El Diario llustrado desde el n. 27 del 27 de abril de 1902. Como si en un acto de franca lucidez el periódico anunciase las tendencias que se desarrollarán pronto en el campo del fotoperiodismo. Junto con ofrecer 150 pesos en premio, las bases de este concurso indican que las instantáneas "deberán necesariamente representar una escena en movimiento", que las personas u objetos sean "animados" o que se "demuestre que la fotografía no ha sido tomada de tiempo". Se advierte igualmente que, aunque el tema se deja a elección de los participantes, serán mejor evaluadas las fotografías que "sean la reproducción de un suceso de importancia, de personajes de actualidad o de escenas de por sí verdaderamente artísticas o curiosas". Como se aprecia, no es la "pose fija" sino el "movimiento" o el carácter "animado" lo que busca promover el periódico. No es la foto "de tiempo" sino el registro instantáneo o de exposición breve. No sabemos si la voz "animado" es una reiteración de "movimiento" o remite a "ánima", a vida o soplo: ¿es el movimiento tan sólo o la viveza de la acción, o ambas cosas, las que debieran representar preferentemente las instantáneas? Probablemente el carácter "animado" que se exige no quiera decir "divertido" o "entretenido", aunque en la frase siguiente se privilegian junto a las escenas "artísticas" también las "curiosas". El otro criterio que se indica es evidentemente la "actualidad" e "importancia" del suceso o personaje.

Estas bases se volverán a publicar en otros números del diario y, a muy poco andar, en el $\mathrm{n}$. 29, del 29 de abril de 1902, aparecerán las primeras instantáneas del concurso (ver figura n. 4). Como se aprecia, no son fotos tomadas en un "estudio" sino en "las carreras", tratan en lo posible de apartarse de la "pose fija" y de reflejar algo de movimiento y espontaneidad. Son básicamente "registros". La atmósfera es "recreativa", y la "autoridad" (el ministro del Ecuador), cuya investidura es señalada en el pie de foto, se ve sin embargo fuera de protocolo, en las carreras y con su familia. Estas dos características (investidura y recreación) son reforzadas por un "anclaje" (Roland Barthes) o leyenda escritural que evita que la foto se dispare en un sentido distinto a esa operación de naturalización (y diferencia a la vez: las carreras de caballos, "el rey Eduardo jugando al golf" en otra foto) de la vida íntima de los poderosos. Más "curiosas" son las dos fotos dedicadas a un "personaje de actualidad", el señor Frégoli, ese "notable transformista" que hacía poco había actuado en el Teatro Municipal con gran éxito, tal como indicábamos páginas más atrás. Un artista y un ministro son pues las figuras que comienzan a ser protagonistas en el deseado reino de las imágenes públicas.

Si seguimos la pista a las instantáneas que se continúan publicando como parte del concurso se puede ver que éstas reproducen cuadros de la vida cotidiana, "acontecimientos" en el sentido débil del término y también lo que habitualmente se llama "accidentes": desde unas regatas sobre el río Valdivia, pasando por unas personas que están esperando o subiendo a un tren en la estación de Parral, hasta los escombros humeantes de un incendio. Las fotos seleccionadas se apartan del modelo del "retrato", tan importante en esta primera época de El Diario llustrado, dejan lo "trascendente" a un lado y se vuelcan a destacar unas "acciones" o "movimientos" que tanto responden al modelo "costumbrista" o "documental" como del ya citado "accidente", cuyo sentido no está en sí sino en el periódico que lo modela como tal.

Como vemos, las fotografías no son aquí ni "códigos cerrados" o autónomos ni "códigos abiertos" o inciertos, dispuestos a decodificaciones múltiples. Si bien estos signos dan cuenta de una "singularidad semiótica" que no permite su asimilación sin más a la "máquina textual" (aunque sí distintos tipos de intercambio entre texto e imagen), el modo cómo se construyen sus significaciones no son independientes de los mensajes o sentidos que se desprenden del conjunto de discursos, imágenes materiales e interacciones que constituyen "el aparato formal de la enunciación"29, es decir, del propio texto periodístico y sus distintas relaciones, y en particular de esa combinación entre modernidad y ensoñación identitaria tan distintiva de El Diario llustrado en 1902. 
1 El presente artículo es un resultado parcial de la investigación FONDECYT n. 1010016.

2 Es sabido que la noción de "autor", entendido como fuente última de sentido, ha perdido al igual que la noción de "obra", concebida como textos capaces de ocultar/manifestar las "intenciones" del "autor", esa evidencia inmediata no problematizada que ciertas tradiciones le venían atribuyendo. Según Michel Foucault es preciso asumir reflexivamente estos agrupamientos arrojándolos "de la sombra en la que reinan". La arqueología del saber. Siglo XXI editores, México, decimotercera edición 1988, capítulo I: "Las unidades del discurso".

3 Estos tópicos y los inmediatamente siguientes se pueden consultar en Carlos Ossandón B./ Eduardo Santa Cruz A.: Entre las alas y el plomo. La gestación de la prensa moderna en Chile. Dibam-Lom-Arcis, Santiago de Chile, 2001. También en Carlos Ossandón B.: El crepúsculo de los sabios y la irrupción de los publicistas. Lom-Arcis, Santiago de Chile, 1998. Un examen del proceso de transformación de la prensa chilena a comienzos del XX se encuentra en Eduardo Santa Cruz A.: El campo periodístico en Chile a principios del siglo XX. Proyecto Fondecyt n. 1010016.

4 Quizá sea importante aclarar que la historia de la prensa no la concebimos como la ampliación o desarrollo de un gran texto único ininterrumpido o sin fisuras, ni tampoco como un ciclo de sustituciones o giros radicales sin coexistencias o pervivencias. Respecto de esto último en otra parte decíamos que no habría que remedar en este punto el esquema de colapso y creación de "epistemes" de Las palabras y las cosas de Michel Foucault.

5 Verónica Mosso G.: El Mercurio y El Diario Ilustrado: dos exponentes en Chile del nuevo periodismo del siglo XX. 1900-1920. Pontificia Universidad Católica de Chile. Tesis para optar al grado de licenciado en Historia, Santiago, 1999, p. 17.

6 Alfonso Valdebenito: Historia del periodismo chileno. 1812-1955. Imp. "Fantasía", 2 Edición, Santiago de Chile, pp. 72 y 73. En 1902 ni El Mercurio de Valparaíso y Santiago ni El Ferrocarril traen "instantáneas".

7 "Las cuatro carretonadas de diarios llegados al mesón volaron a los cuatro extremos de la ciudad, impelidas como por un huracán de entusiasmo. Aquello era un infierno: gritos, trompadas, estrellones, apóstrofes, los chicos trepados unos sobre otros, los empleados del diario vendiendo en mangas de camisa..." Así describe El Mercurio de Santiago su "entrada triunfal" al siglo veinte. En Grandes Noticias. 1900-1938. María Angélica de Luigi. El Mercurio S.A.P., Santiago, 1985, pp. 5 y 6.

8 Este periódico que al comienzo se llamó Las Ultimas Noticias de El Mercurio, fundado por Agustín Edwards Mac Clure, habría consolidado la dimensión vespertina de la prensa. Aun cuando no es el primer periódico que tiene este rasgo, según Alfonso Valdebenito "creó entre nosotros el tipo de diario de la tarde", tan completo como los de la mañana (Op. cit.: pp. 71 y 72 )

9 Carta de Joaquín Díaz Garcés a Agustín Edwards Mac Clure, 22.5.1902, citada por Patricio Bernedo y Eduardo Arriagada en "Los inicios de El Mercurio de Santiago en el epistolario de Agustín Edwards Mac Clure (1899-1905)", Historia, Vol. 35, Instituto de Historia, Universidad Católica de Chile, 2002, p. 18. Una investigación que intenta discutir tópicos consagrados sobre los orígenes de la prensa moderna en Chile se encuentra en Carolina Cherniavsky B.: El Ferrocarril y El Mercurio de Santiago (1855-1911) ¿El fin de una época y el comienzo de otra en la prensa chilena? Tesis para optar al grado de Licenciado en Historia. Pontificia Universidad Católica de Chile, Santiago, 1999. Sobre las nuevas publicaciones para niños se puede consultar Carlalí Villalba, Francisca Araya, Bárbara Fuenzalida, Iván Valdés, Alcia Infante: El Peneca: de santo a rebelde. Tesis para optar al grado de Licenciado en Comunicación Social, Universidad de Chile, 2002. Sobre revistas magazinescas ver Eduardo Santa Cruz A.: "Modernización y cultura de masas en el Chile de principios del siglo veinte: el origen del género magazine, en Comunicación y Medios, Año 12 , n. 13, Universidad de Chile, Facultad de Ciencias Sociales, Departamento de Investigaciones Mediáticas y de la Comunicación, segundo semestre 2002. Y Carlos Ossandón B.. "Zig-Zag o la imagen como gozo", en Mapocho, Dibam, n. 51, Santiago, primer semestre 2002.

10 Raúl Silva Castro: Prensa y Periodismo en Chile (1812-1956). Ediciones de la Universidad de Chile, Santiago, 1958, p. 367.

11 Como se sabe, el relato de "sucesos" o de "hechos", así como el discurso de la "objetividad", constituyen componentes importantes de las estrategias periodísticas modernas. No se equivoca pues Raúl Silva Castro cuando indica que El Mercurio de Valparaíso "se aparta desde el primer momento de los usos que hasta entonces habían sido habituales en la prensa chilena" (Op. cit., p. 130). En efecto, su primer número de 1827 que relata un "accidente", que le costó la vida a un comandante de guardia a manos de un oficial de la marina inglesa, es un hito que pautará el desarrollo posterior de la prensa. El Diario Ilustrado es ciertamente tributario de este constructo típicamente moderno. El "hecho", su "actualidad", su descripción y clasificación, le permitirán fabricar-segmentar un "presente" del cual quedará irremediablemente atado.

12 Muy lejos de la "neutralidad" es el tratamiento que El Diario Ilustrado dará algunos años después a los sucesos ligados al "pope" Julio, un predicador a cuya sombra, dice el diario, "se agrupan hoy tribus distintas: radicales, socialistas, anarquistas y esa masa inconsciente que corre al tumulto por amor al desorden". Según el diario, "una turba de los bajos fondos sociales, azuzada por el clérigo Julio y el anarquista Bustamante y otros desconocidos", no sólo causó destrozos y heridos sino también "pretendió atacar a los que formaban la procesión del Santo Sepulcro": números 1085 y 1110 del 28 marzo y 23 de abril de 1905 respectivamente. 
13 Según Manuel Vicuña, el Teatro Municipal es un buen ejemplo para entender la amalgama entre "patricios" y "advenedizos" que se hace ostensible en esta época. Un público más heterogéneo o entrelazado se habría dado cita en el nuevo Municipal reconstruido después de un incendio en la década de 1870. "Instituciones como el Teatro Municipal dice - representaron canales informales de ascenso social y medios propicios a la asimilación cultural de los nuevos elementos". La belle époque chilena. Editorial Sudamericana, Santiago de Chile, 2001, pp. 27 y 28.

14 Sobre los gustos de la época ver Alfonso Calderón: 1900. Editorial Universitaria, Santiago de Chile, $1980, \mathrm{pp}$. 183 y sgs. Bernardo Subercaseaux: Fin de Siglo. La época de Balmaceda. Editorial Aconcagua, Chile, 1988, pp. 255 y sgs. Armando de Ramón: Santiago de Chile. Editorial Mapfre, 1992, Madrid, pp. 184 a 187.

15 Stella Martini: Periodismo, noticia y noticiabilidad. Grupo Editorial Norma, Colombia, 2000, p. 20.

16 Julio Ramos: Desencuentros de la modernidad en América Latina. Literatura y política en el siglo XIX. F. C. E., México, 1989, p. 123.

17 El Diario Ilustrado es el primer periódico que lleva como logotipo, al lado de una paleta y de un pote de pinceles, una cámara fotogrática (de fuelle).

18 Bernardo Subercaseaux: Genealogía de la Vanguardia en Chile. Ediciones Facultad de Filosofía y Humanidades, Universidad de Chile, s/f, p. 93.

19 Armando de Ramón: Op. cit., capítulo IV: "La ciudad primada (1850-1930)". Consultar también José Luis Romero: Latinoamérica: las ciudades y las ideas. Siglo veintiuno editores, Argentina, 4º edición, 1986, pp. 247 y sgs.

20 Julio Ramos: Op. cit., p. 124.

21 Friedrich Nietzsche: Sobre el porvenir de nuestras escuelas. Tusquets Editores, Barcelona, 2000. En una de sus notas, Andrés Sánchez Pascual (prologuista y traductor de Nietzsche) escribe: "La "lectura de periódicos" fue un tema tocado por Nietzsche desde muy temprano, y siempre en sentido negativo /.../ En más de una ocasión compara esa costumbre a la "diaria visita a la cervecería", y dice que es un sustitutivo de las "oraciones diarias" (en Friedrich Nietzsche: Más allá del bien y del mal. Alianza Editorial, Madrid, 1994, nota 5,. p. 262).

22 Sobre éste y otros temas relacionados, ver Eliseo Verón: "De la imagen semiológica a las discursividades. El tiempo de una fotografía", en Isabel Veyrat-Masson y Daniel Dayan (comps.): Espacios públicos en imágenes. Editorial Gedisa Barcelona, 1997.

23 En el artículo "Fotógrafos de prensa. Testigos directos y espejos de identidad" Juan Domingo Marinello señala: "Es un error común y repetido sostener que la primera fotografía periodística impresa aparece en El Diario Ilustrado en el año 1902. En rigor debiera indicarse que este hecho solamente constituye un hito en cuanto a una publicación "diaria". En efecto, ya en el año 1897 en La Revista Ilustrada, de Santiago, impresa por "Heliograbados e impresos del Universo", se publicaban semanalmente fotografías periodísticas impresas en trama, a gran tamaño" /.../ "Incluso en la misma década, La Lira Popular, incluye clichés fotográficos. Pero no será en los periódicos, sino en las revistas ilustradas /se refiere a Zig-Zag principalmente/, donde el fotoperiodismo tendrá una verdadera época dorada durante las dos primeras décadas del novecientos" (p. 125). En Abel Alexander, Margarita Alvarado et alia: Historia de la fotografía en Chile: rescate de huellas en la luz. Centro Nacional Patrimonio Fotográfico, Chile, Octubre 2000. De Juan Domingo Marinello ver también: "Grafías de la oralidad periodística", en Patrimonio Cultural. Revista de la Dirección de Bibliotecas, Archivos y Museos. Año VI, n. 22, Chile, invierno de 2001.

24 Sobre el "derecho" a ser fotografiado ver Alicia Entel et alia: Escuela de Frankfurt. Razón, arte y libertad. Eudeba, Argentina, 1999, p. 154

25 A este respecto Eliseo Verón hace interesantes alcances. Dice: "Desde los comienzos mismos de la fotografía, se impone un empleo de ésta que retoma los códigos pictóricos del retrato. Los personajes notables, comenzando por el propio emperador, se hacen fotografiar del mismo modo en que antes se hacían pintar (Rouillé 1985). En este caso, la estrategia enunciativa, al retomar las reglas de producción del retrato pintado, expresa como éste, una voluntad de ejemplaridad: trabajada por la estilística del retrato pintado, la exposición fotográfica tiene un resabio de eternidad. En el terreno fotográfico, tenemos pues una primera figura enunciativa de la neutralización de las condiciones específicas de la "toma de vistas": el referente (empleando la terminología de Barthes) está destemporalizado". Op. cit., p. 58.

26 Hernán Rodríguez Villegas: "Historia de la fotografía en Chile. Registro de daguerrotipistas, fotógrafos, reporteros gráficos y camarógrafos. 1840-1940", en Boletín de la Academia Chilena de la Historia. Año LII, n. 96, Santiago de Chile, 1985/1986, p. 190.

27 Eliseo Verón: Op.cit., p. 59.

28 "El último choque de tranvías". En el pie se lee: "Dibujo del violento choque de tranvías ocurrido a las dos y media de la tarde del Miércoles 16, en la Plaza de la Independencia esquina de Catedral, hecho por nuestro primer dibujante, don Santiago Pulgar, con apuntes tomados del natural" (El Diario Ilustrado, 19 de abril de 1902).

29 Roger Chartier: "Poderes y límites de la representación. Marin, el discurso y la imagen" en Escribir las prácticas. Manantial, Argentina, 1996, pp. 83 y otras. 
